\title{
The public and patients should have their say in HTA
}

Leela Barham ${ }^{1}$

\section{INTRODUCTION}

Health Technology Assessment (HTA) is defined as «a multidisciplinary process that summarizes information about the medical, social, economic and ethical issues related to the use of a health technology in a systematic, transparent, unbiased, robust manner. Its aim is to inform the formulation of safe, effective, health policies that are patient focused and seek to achieve best value» [1]. And to really be that in practice, patients need to be involved, not least to respond to the need for HTA to be patient-focused as outlined in the above definition.

The findings that result from appraisal can be very influential in either providing patient access to a new technology or limiting access. The approach that countries take to HTA varies. This editorial draws on selected literature and the example of the National Institute for Health and Clinical Excellence (NICE) in England to explore why patients, and the public more generally, should be involved and how that can be achieved in theory and practice.

\section{WHY INVOLVE THE PUBLIC AND PATIENTS IN HTA?}

There are a number of reasons why the public and patients should be involved in HTA.

As NICE acknowledges in their work, patients can [2]:

- provide a unique source of evidence on the personal impact of a disease and how technology can make a difference;

- identify shortcomings in the published research.

Involvement of patients also supports a more transparent approach, making more explicit the normative judgments made in assessing a technology [3].

NICE also acknowledges that given their decisions affect the allocation of public funds, often towards certain groups of patients and given limited funds, away from other groups of patients (or potential patients in the future), that the public more broadly needs representation [4].
The National Institute for Health Research (NIHR) HTA program, which undertakes independent HTA in the UK, also recognizes the role of patients and public. They have taken a decision to actively involve patients in their work program. They state that: «HTA research must address the questions that are important to those who use NHS services, and to ensure that it does this the HTA program actively involves members of the public throughout the research process» [5].

There is evidence that involvement is also considered important across the HTA field. Over half of the members of the International Network of Agencies for Health Technology Assessment (INAHTA) who responded when surveyed in 2005, said they involve consumers in their HTA work. Further, $83 \%$ said that they intended to involve them in the future [6]. Bridges and Jones suggest that patients are the most important stakeholder amongst many in HTA [7].

However, there remains concern that patients' perspective are rarely included, perhaps because they are seen as anecdotal, biased views [3].

\section{HOW CAN YOU INVOLVE THE PUBLIC AND PATIENTS IN HTA?}

The options for involvement are many and varied, and that provides a menu of options for those undertaking HTA to develop an approach that works in their specific context.

Facey et al. highlight that there are a number of research approaches [3]:

- systematic reviews of qualitative research;

- primary research including:

- qualitative methods such as individual in-depth interviews and focus groups

- quantitative methods such as surveys; including tools such as the EQ 5D.

Using NICE as a practical example, NICE provides a range of options including [8]:

- Allowing the public and patients to make suggestions for topic areas. This helps to involve the public and patients when not

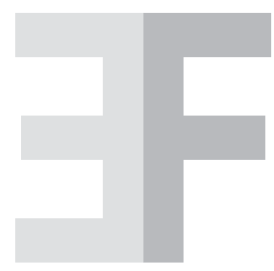

EDITORIAL 
all technologies can be assessed and subject to full appraisal.

- Inviting responses to the development of NICE guidance (all the way from scoping, draft, to final guidance). This provides a number of opportunities as work progresses for the public and patients to comment across the key stages of HTA. This includes commenting on the interpretation of the evidence on both costs and benefits of treatment as NICE reviews the evidence and conducts it's deliberations.

- Inviting public and patient members on to Working Groups.

- Including public and patient members on NICE Appraisal Committees (ACs). ACs made recommendations to the NHS on the use of technologies. There are 12 lay members of the 30-33 total members in each of the four committees, who have a tenure of 3 years with the possibility of extending to 10 years.

- Including public and patient members on the Partners Council (PC). The PC reviews NICE's annual report and provides a forum for exchange of ideas, concepts and future plans. There are 49 places, with patient/public representatives accounting for 6 places.

- Inviting the public to be part of the Citizens Council. Thirty members of the public come together to debate questions set by NICE to provide guidance that underpins NICE Appraisal Committee recommendations. Members have a tenure of 3 years, and 10 members change every year.

- Inviting the public and patients to contribute to the NICE database on implementation.

This means that the public and patients have numerous ways to be involved, which offer lesser or greater commitment for individuals and organizations. The relative success of each approach has not to the knowledge of the author been considered.

\section{WHAT HAPPENS WHEN YOU INVOLVE THE PUBLIC AND PATIENTS?}

Final decisions made as a result of HTA are the result of a complex set of factors (i.e. the clinical and economic evidence) and deliberations. In addition, "stakeholder persuasion" has been identified as a factor in NICE recommendations [9]. Disentangling the impact of each factor is difficult, however there is evidence that patient organization submissions can increase the likelihood of a routine rather than restricted use recommendation [10].

\section{MORE NEEDS TO BE DONE}

Few studies are known to the author about the approach to involvement the public and patients in HTA. However, those studies that are available suggest that there may be goodwill to those patients who took part in developing clinical guidelines with NICE, but their perception of influence they had versus others (such as health professionals, health economists and the pharmaceutical industry) was limited [11]. There is also a need to support patient representatives and provide training and information [12].

Overall, more needs to be done to deliver on the potential of involvement with the public and patients [8]. In the authors' view the first step is to ensure that there is a recognition of both the legitimate role for public and patients and the value that they can bring to decision making, and the next to explore what the practical options may be for involvement. Given the myriad number of ways HTA is applied in practice, this should start with a look at the main options in use in other countries, such as the NICE example above, and then to apply judgment as to what is appropriate in the specific context. Lastly there should be ongoing evaluation and adaption to ensure that public and patient involvement is effective and costeffective. This will provide a rich source of insights to adapt and learn over time, to ensure that HTA is truly public and patient-focused.

\section{REFERENCES}

1. http://www.eunethta.eu/Public/About_EUnetHTA/HTA/ [accessed May 29 ${ }^{\text {th }}$ 2012]

2. http://www.nice.org.uk/getinvolved/patientandpublicinvolvement/patient_and_public_involvement.jsp [accessed March 2010 Mar 2]

3. Facey K, Boivin A, Gracia J, et al. Patients' perspectives in health technology assessment: a route to robust evidence and fair deliberation. IJTAHC 2010; 26: 334-40

4. Rawlins MD. Pharmacopolitics and deliberative democracy. Clinical Medicine 2005; 5: 471-5. Available at: http:// docserver.ingentaconnect.com/deliver/connect/rcop/14702118/v5n5/s13.pdf?expires=1268410948\&id=55557725 
$\&$ titleid $=5200003 \&$ accname $=$ Guest + User\&checksum $=$ A3B2BCF259B5226F1A380548C4AA5AE8 [last accessed May 2012]

5. http://www.hta.ac.uk/public/index.shtml [last accessed May 2012]

6. Hailey D, Nordwall M. Survey on the involvement of consumers in health technology assessment programs. IJTAHC 2006; 22: 497-9; http://dx.doi.org/10.1017/S0266462306051427

7. Bridges JFP, Jones C. Patient-based health technology assessment: a vision of the future. IJTAHC 2007; 23: 30-5; http://dx.doi.org/10.1017/S0266462307051549

8. Barham L. Public and Patient Involvement at the UK National Institute for Health and Clinical Excellence. Patient 2011; 4: 1-10. doi: 10.2165/11586090-000000000-00000

9. Rawlins M, Barnett D, Stevens A. Pharmacoeconomics: NICE's Approach to Decision-making. Br J Clin Pharmacol 2010; 70: 346-9

10. Dakin HA, Devlin NJ, Odeyemi IA. "Yes", "No" or "Yes, but"? Multinomial modelling of NICE decision-making. Health Policy 2006; 77: 352-67

11. Quennell P. Getting a word in edgeways? Patient group participation in the appraisal process of the National Institute for Health and Clinical Excellence. Clinical Governance 2003; 8: 39-45

12. NICE Patient Involvement Unit A report on a study to evaluate patient/carer membership of the first NICE Guideline Development Groups June 2004. Available at: http://www.nice.org.uk/niceMedia/pdf/PIU_Evaluation_report_270704.pdf [last accessed May 2012] 